\title{
Selective absorption enhancement in organic solar cells using light incoupling layers
}

\author{
Jan Meiss, ${ }^{\text {a) }}$ Mauro Furno, Steffen Pfuetzner, Karl Leo, and Moritz Riede \\ Institut für Angewandte Photophysik, Technische Universität Dresden, Dresden D-01062, Germany
}

(Received 9 October 2009; accepted 13 January 2010; published online 15 March 2010)

\begin{abstract}
We show that capping layers of tris-(8-hydroxy-quinolinato)-aluminum $\mathrm{Alq}_{3}$ enable increased absorption and photocurrent in organic solar cells (OSCs) when using transparent metal films as top electrodes. Furthermore, by varying the capping layer thickness, the optical field in the OSC is tuned for selective wavelengths, opening a possibility of influencing the external quantum efficiency for specific absorber materials. It is described how a second maximum of the optical field intensity can be utilized, which is a concept significant for tandem solar cells. Indium tin oxide (ITO)-free OSCs are presented which show the influence of capping layer on efficiency, saturation, fill factor, and open-circuit voltage, with numerical calculations supporting the experimental evidence of layer-selective enhancement. (C) 2010 American Institute of Physics. [doi:10.1063/1.3311559]
\end{abstract}

\section{INTRODUCTION}

In recent years, organic solar cells (OSCs) have attracted considerable interest as a potential cost-efficient alternative to current silicon solar cells. Since the first major breakthrough with a copper phthalocyanine/perylene derivative heterojunction by Tang, ${ }^{1}$ new materials and concepts resulted in certified power conversion efficiencies of $6.07 \%$ for a $2 \mathrm{~cm}^{2}$ small-molecule OSC, ${ }^{2,3}$ competing with $7.9 \%$ at $0.047 \mathrm{~cm}^{2}$ for the most efficient polymer OSC. ${ }^{4}$ An issue recognized by the OSC community is the scarcity of indium, resulting in increasing prices of tin-doped indium oxide (ITO), the standard transparent conductive substrate coating for OSC. Since ITO is furthermore brittle and less suitable for flexible devices, an increasing effort is made to find alternative transparent conductive materials, e.g., conductive polymers, ${ }^{5,6}$ metals, ${ }^{7,8}$ aluminum-doped zinc oxide, ${ }^{9}$ solution-processed graphene, ${ }^{10} \mathrm{Ag}$ wires, ${ }^{11}$ or carbon nanotubes. ${ }^{12-14}$

Ultimately, for successful competition in commercial applications, the use of tandem solar cells is advantageous in order to harvest a broad part of the solar spectrum efficiently. In this case, an understanding of the optical field distribution within the OSC stack is necessary, together with methods to selectively influence its amplitude and reduce external reflection. This will open the possibility to use optical spacer layers to improve current matching and ensure maximum utilization of the absorber layers. ${ }^{15}$ These issues can be addressed by using capping layers on top of a transparent contact, as has been proposed ${ }^{16}$ for single solar cells and has been tested in first experiments. ${ }^{16,17}$

In the current work, we describe a series of systematic experiments to study the influence of the thickness of tris-(8hydroxy-quinolinato)-aluminum $\left(\mathrm{Alq}_{3}\right)$ capping layers on photovoltaic properties and field distribution within an OSC. In previous experiments with capping layers, ${ }^{17}$ it was found that the photocurrent of OSC can be increased upon addition of an organic light incoupling layer by lowering the external

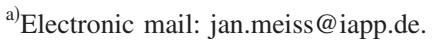

reflection and influencing the optical field. Within the range of data available for these studies, the improvement of device performance was found to be based on $J_{\mathrm{SC}}$, with only very minor influences of the capping layer on other characteristic parameters. External quantum efficiency (EQE) measurements showed an almost wavelength-independent correlation of EQE and capping layer thickness.

The present study is performed with a systematic variation of capping layer thickness over a wide range, with detailed simulations and experimental characterization. We find that a capping layer significantly modifies specific absorption wavelengths, at the same time influencing all major device characteristics, i.e., open circuit voltage, fill factor, and saturation. An oscillating behavior of fundamental solar cell parameters is observed, depending on capping layer thickness. These conclusions are derived from current voltage data and the wavelength-resolved EQE measurements. Numerical simulations of optical field distribution and absorbed photon flux confirm the wavelength- and layer-selective absorption enhancement of specific absorber layers. It is shown that there are capping layer thicknesses that lead to high total device performance, but that more detailed fine-tuning of absorption within the OSC is possible.

Our findings lead to a better understanding of optical processes within multilayer organic optoelectronic devices. Since current matching is decisive for tandem OSC, we expect that the precise control of capping layers is critical for inverted tandem OSC so that field enhancement for specific wavelength ranges or absorber layers can be fully utilized.

\section{EXPERIMENTAL}

The investigated OSCs are fabricated in a custom-made vacuum system (K.J. Lesker, U.K.) at a base pressure of $10^{-8}$ mbar, using shadow masks. Boron float glass (Schott Borofloat 33, purchased from PRINZ OPTICS) precleaned with acetone and ethanol and pretreated in oxygen plasma is used as substrate. 16 samples are made on the same substrate in one run, ensuring reproducible and comparable conditions 


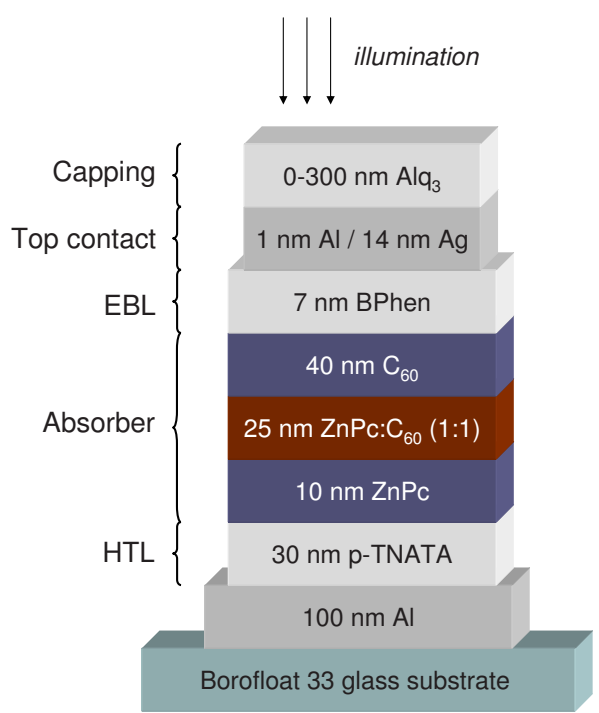

FIG. 1. (Color online) Solar cell stack: substrate, intransparent metal back electrode, hole transport layer, absorber, EBL, semitransparent metal top contact, and organic capping layer.

for all layers and allowing for intentional variation of only single layers or parameters.

A metal back contact of $100 \mathrm{~nm} \mathrm{Al}$ is deposited, followed by $1 \mathrm{~nm}$ NDP2 (Novaled AG, Dresden, Germany). ${ }^{18}$ As hole transporting material, $30 \mathrm{~nm}$ of 10 wt $\%$ pdoped 4,4', 4"-tris(1-naphthylphenylamino)-triphenylamine (TNATA) is used. For light absorption, a hybrid bilayer system is deposited, consisting of a layer of zinc phthalocyanine $(\mathrm{ZnPc})(10 \mathrm{~nm})$ followed by a layer of coevaporated $\mathrm{ZnPc}: \mathrm{C}_{60}(25 \mathrm{~nm}$, volume ratio $1: 1)$ as bulk heterojunction $(\mathrm{BHJ})$. After an additional absorber and transport layer of $\mathrm{C}_{60}$ (40 nm), $7 \mathrm{~nm}$ of 4,7-diphenyl-1,10-phenanthroline (BPhen) is used as exciton blocker [exciton blocking layer (EBL)]. All materials except the dopant had been purified at least twice by vacuum gradient sublimation. As transparent top contact, $1 \mathrm{~nm} \mathrm{Al}$ followed by $14 \mathrm{~nm} \mathrm{Ag}$ is used to ensure a good compromise of transmission and conductivity. ${ }^{7}$ The parameter varied in the discussed samples is the thickness of the transparent wide-gap $\mathrm{Alq}_{3}$ capping layer, which is used in thicknesses of 0-300 $\mathrm{nm}$. The capping layer is evaporated in situ on top of the metal contact. The complete device stack is shown in Fig. 1. The completed solar cells are encapsulated with a transparent encapsulation glass and $\mathrm{N}_{2}$-filled cavity in a nitrogen glovebox attached to the vacuum deposition chamber, then stored at ambient conditions. Typical solar cell areas are around $6.7 \mathrm{~mm}^{2}$ (measured using a light microscope).

Current voltage characteristics are recorded using a source measurement unit 236 SMU (Keithley) under an AM $1.5 \mathrm{~g}$ sun simulator, monitored with a Hamamatsu S1337 silicon photodiode with respect to which intensities are measured. All devices presented here are measured through the encapsulation glass. The reported values are not corrected for spectral mismatch. Calculations using EQE measurements, the simulator spectrum, and the spectral response of the reference photodiode indicate that the mismatches of all devices in the current work are within $1 \%$ of each other, ensuring consistent data.

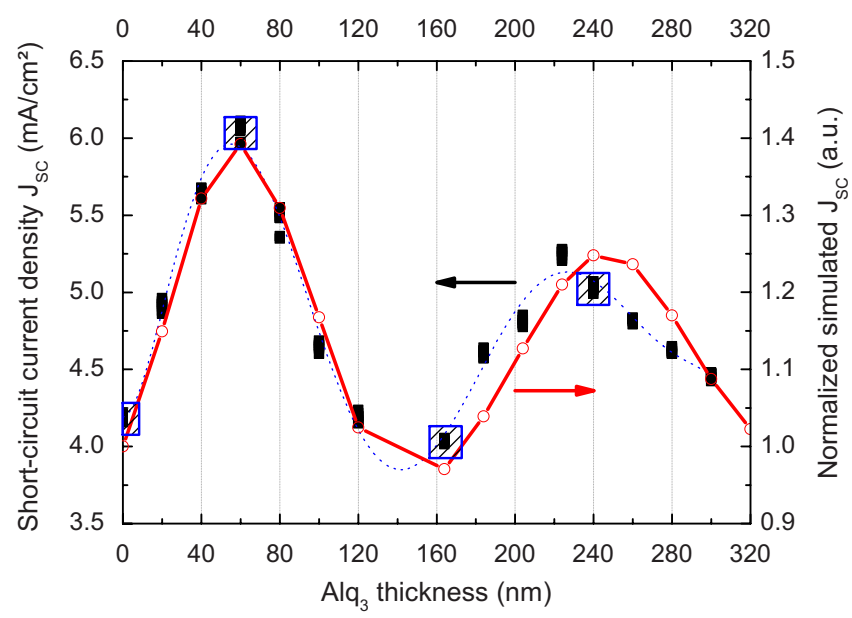

FIG. 2. (Color online) Comparison of measured (left axis) and simulated (right axis) short-circuit current densities. Filled squares: experiment. Dotted line: guide to the eyes. Empty circles: normalized simulation data, assuming AM 1.5g illumination and $100 \%$ internal quantum efficiency. The four crosshatched boxes at $0,60,164$, and $240 \mathrm{~nm}$ capping layer thickness mark four solar cell devices which are characterized in more detail, representing current/efficiency maxima and minima.

EQE is measured employing lock-in techniques (Signal Recovery SR 7265 lock-in amplifier) in a custom-made setup with Xe illumination and a Newport Oriel Apex monochromator illuminator. The samples are measured under bias illumination through a photomask having an aperture of $2.958 \mathrm{~mm}^{2}$.

Optical simulations are performed using a numerical code based on the transfer matrix approach. This technique uses refractive index $n$, extinction coefficient $k$ (obtained from reflection and transmission measurements), and the layer thickness to calculate, e.g., photon absorption, shortcircuit current, and distribution of the optical field within the solar cell. ${ }^{19}$ The model is purely optical and assumes $100 \%$ internal quantum efficiency in the active layers.

Ideally, simulations should be performed by treating the device as a stack consisting of the organic layers, the metal electrodes and the capping layer (all treated coherently), an incoherent $\mathrm{N}_{2}$-filled void between OSC stack and encapsulation glass (as consequence of the encapsulation procedure), and the incoherent encapsulation glass itself, with illumination coming from ambient air through the encapsulation glass. We verified by comparing simulations and experiments that neglecting the $\mathrm{N}_{2}$-filled void between OSC stack and encapsulation glass would lead to erroneous results, disagreeing quantitatively and qualitatively with the measured data. However, simulations of total device absorption show that one can realistically approximate the device by neglecting both void and glass, i.e., considering only the OSC stack and the interface $\mathrm{Alq}_{3}$-air with coherent treatment. All simulation data shown in this letter are based on this approximation.

\section{RESULTS}

Figure 2 shows a plot of the short-circuit current $J_{\mathrm{SC}}$ versus capping layer thickness, with the measured values as filled squares (the dotted line is a guide to the eyes). The empty circles represent the normalized calculated $J_{\mathrm{SC}}$, as ob- 
TABLE I. Solar cell characteristics.

\begin{tabular}{ccccc}
\hline \hline $\begin{array}{c}\mathrm{Alq}_{3} \text { capping } \\
(\mathrm{nm})\end{array}$ & $\begin{array}{c}J_{\mathrm{SC}} \\
\left(\mathrm{mA} / \mathrm{cm}^{2}\right)\end{array}$ & $\begin{array}{l}V_{\mathrm{OC}} \\
(\mathrm{V})\end{array}$ & $\begin{array}{c}F F \\
(\%)\end{array}$ & $\begin{array}{c}\eta \\
(\%)\end{array}$ \\
\hline 0 & 4.21 & 0.529 & 57.0 & 1.27 \\
60 & 6.11 & 0.542 & 55.7 & 1.84 \\
164 & 4.04 & 0.528 & 56.9 & 1.21 \\
240 & 4.99 & 0.540 & 57.1 & 1.54 \\
\hline \hline
\end{tabular}

tained by the model. Both experiment and simulation exhibit an oscillating behavior that results from the influence of different capping layer thicknesses on interference within the device, combined with an antireflection effect. Four data points are marked with crosshatched boxes; they represent no capping layer, $60 \mathrm{~nm}$ capping layer (first maximum), 164 $\mathrm{nm}$ capping layer (first minimum) or $240 \mathrm{~nm}$ (second maximum), respectively. These four data points are now discussed in more detail to elucidate the effect of $\mathrm{Alq}_{3}$ on field distribution and EQE, with the characteristic parameters of these devices shown in Table I.

The major and most visible influence of the $\mathrm{Alq}_{3}$ layer thickness is reflected in $J_{\mathrm{SC}}$, which ranges from 4.04 to $6.11 \mathrm{~mA} / \mathrm{cm}^{2}$. Figure 3 illustrates a plot of current voltage data of different $\mathrm{Alq}_{3}$ layer thicknesses under illumination and in the dark (inset). While the capping layer leads to no physical difference in the device stack between the electrodes, it is evident that the charge carrier generation, resulting from light absorption, is strongly influenced and leads to an improvement of the photocurrent of $50 \%$ when an $\mathrm{Alq}_{3}$ layer thickness of $60 \mathrm{~nm}$ is chosen, compared to the sample with no capping layer.

The relatively high $F F$ of $55.5 \%-57.3 \%$ hint at only weak recombination. The lowest $F F=55.7 \%$ was measured for the sample having the highest short-circuit current density $J_{\mathrm{SC}}=6.11 \mathrm{~mA} / \mathrm{cm}^{2}$. It is expected that for even higher photocurrents, ultimately the quality of charge carrier transport pathways will limit $F F$ and efficiency $\eta$ through recom-

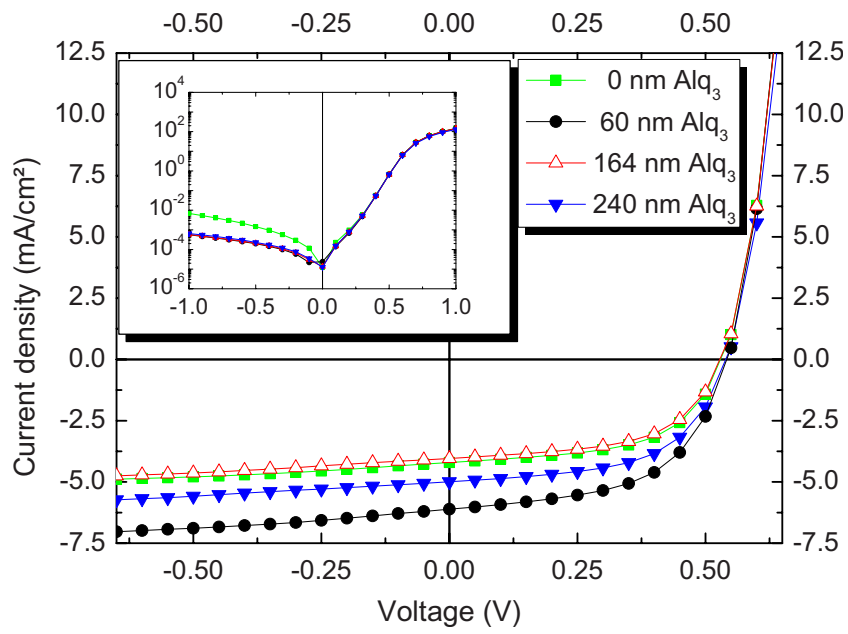

FIG. 3. (Color online) Current voltage curves of OSC with different $\mathrm{Alq}_{3}$ layer thicknesses, under illumination. Filled squares: $0 \mathrm{~nm} \mathrm{Alq}_{3}$. Filled circles: $60 \mathrm{~nm}$. Empty triangles: $164 \mathrm{~nm}$. Filled upside-down triangles: 240 $\mathrm{nm}$ capping layer. Inset: current voltage curves of the same devices in the dark on a semilog scale.

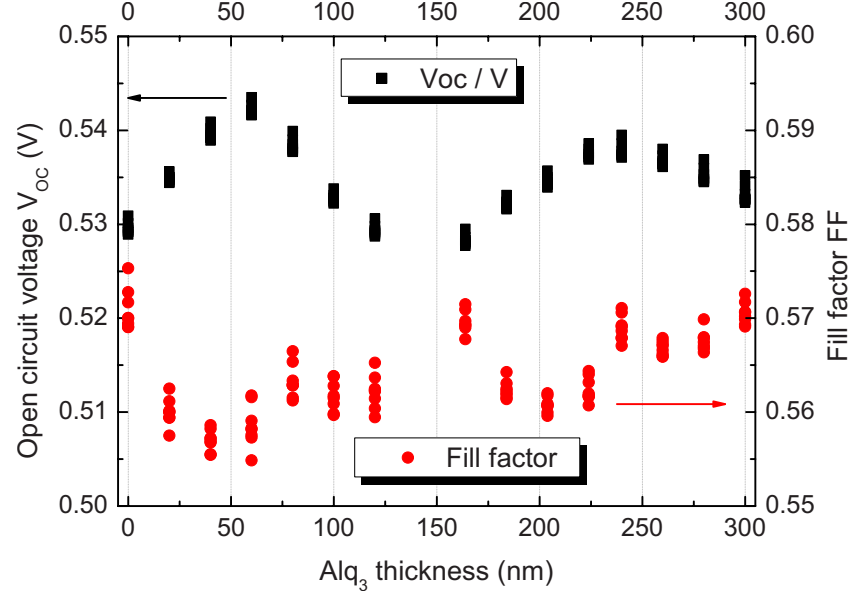

FIG. 4. (Color online) Plot of open circuit voltage $V_{\mathrm{OC}}$ (filled squares) and fill factor $F F$ (filled circles) vs $\mathrm{Alq}_{3}$ layer thickness.

bination mechanisms. The $F F \approx 57 \%$ are obtained for $J_{\mathrm{SC}}$ $\leq 5 \mathrm{~mA} / \mathrm{cm}^{2}$, while for higher photocurrents $F F$ decreases due to higher charge carrier density which increases recombination. Again, it is stressed that this electrical effect results only from increased charge carrier densities in the device, since the electrode is not modified in any way. The diodes in forward direction for $V>V_{\mathrm{OC}}$ exhibit the same behavior independent of $\mathrm{Alq}_{3}$ capping, underlining that the electrode performance (e.g., the series resistance $R_{\mathrm{S}}$ ) is not changed.

Figure 4 documents the influence of capping layer thickness on open circuit voltage $V_{\mathrm{OC}}$ (filled squares) and fill factor $F F$ (filled circles), Fig. 5 the effect on power conversion efficiency $\eta$ and saturation $S$, with the saturation being defined as $J(-1 \mathrm{~V}) / J_{\mathrm{SC}}$. The oscillatory behavior observed in the short circuit current is evident in these parameters as well.

There is a clear correlation of photocurrent $J_{\mathrm{SC}}$ and $V_{\mathrm{OC}}$. $V_{\text {OC }}$ represents the quasi-Fermi level splitting, influenced by $J_{\mathrm{SC}}$, around the donor-acceptor interfaces. ${ }^{20} V_{\mathrm{OC}}$ in $\mathrm{BHJ}$ of OSC is mainly described by the quasi-Fermi level splitting between the highest occupied molecular orbital (HOMO) of

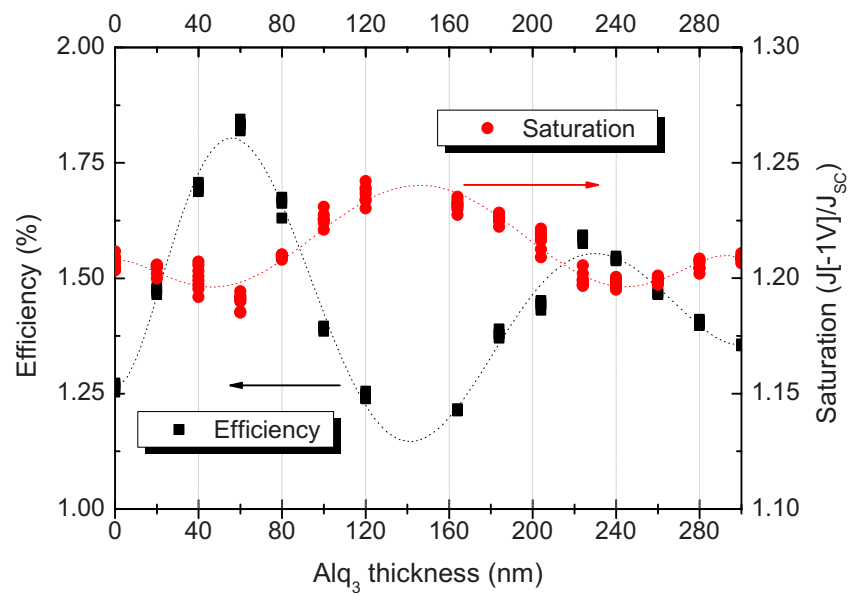

FIG. 5. (Color online) Plot of power conversion efficiency $\eta$ (filled squares) and saturation $S$ (filled circles) vs $\mathrm{Alq}_{3}$ layer thickness. The lines are guide to the eyes. 
the donor molecules and the lowest unoccupied molecular orbital (LUMO) of the acceptor, with an approximation for the maximum voltage being

$$
V_{\mathrm{OC}}=\frac{1}{\mathrm{e}}\left(E_{\mathrm{LUMO}, \mathrm{A}}-E_{\mathrm{HOMO}, \mathrm{D}}\right)-d E
$$

where e is the elementary charge and $d E$ the exciton binding energy ${ }^{21}$ which is often in the range of $0.3-0.7 \mathrm{eV}$. However, the origin of $V_{\mathrm{OC}}$ is so far not completely understood and subject of ongoing discussion. ${ }^{22-25}$ In contrast to inorganic solar cells, $V_{\mathrm{OC}}$ of OSC does not necessarily correlate to the built-in voltage $V_{\mathrm{bi}}$ (Ref. 26) and is often largely independent of the work functions of external electrodes; a description of $V_{\mathrm{OC}}$ in terms of the classical diode equation has been largely unsuccessful, leading to the development of extended models. $^{27,28}$

To ensure reliable and reproducible data, four OSCs are created for each $\mathrm{Alq}_{3}$ layer thickness in one run under the same processing conditions. All 60 devices are measured under the same conditions at the same time, having experienced the same degradation (if any). This allows for the detection of relatively small variations of $V_{\mathrm{OC}}$. The experimentally determined values of $0.528-0.542 \mathrm{~V}$ are typical for $\mathrm{ZnPc}: \mathrm{C}_{60}$ BHJ. ${ }^{29}$ The relationship of $J_{\mathrm{SC}}$ and $V_{\mathrm{OC}}$ shows increasing voltages for increasing currents that is attributed to higher charge carrier density within the BHJ due to higher photocurrents: ${ }^{26}$ the strength of the quasi-Fermi level splitting depends on the charge carrier densities and is described for an arbitrary device by

$$
\begin{aligned}
& E_{Q F, e}=E_{C}-k_{B} T \ln \frac{N_{C}}{n_{e}}, \\
& E_{Q F, h}=E_{V}+k_{B} T \ln \frac{N_{V}}{n_{h}},
\end{aligned}
$$

with $E_{Q F, e}$ and $E_{Q F, h}$ being the quasi-Fermi energies for electrons and holes, $E_{C}$ and $E_{V}$ the energies of conduction and valence band, $k_{B}$ the Boltzmann constant, $T$ the temperature, $N$ the densities of states, and $n$ charge carrier densities. Therefore, a correlation of splitting and photocurrent is expected. This is observed in terms of the connection of $V_{\mathrm{OC}}$ and $J_{\mathrm{SC}}$, where $\mathrm{Alq}_{3}$ thicknesses that lead to high $J_{\mathrm{SC}}$ also lead to increased $V_{\mathrm{OC}}$.

The $F F$ show an inverse oscillation compared to $J_{\mathrm{SC}}$ and $V_{\mathrm{OC}}$. The $F F$ of all devices are relatively high, with values ranging from $55 \%$ to $58 \%$, hinting at good charge extraction from the BHJ with low barriers. For highest photocurrents, obtained in the maxima, the lowest $F F$ are observed; this correlates to charge carrier recombination caused by the higher charge carrier density. However, it is noteworthy that the variation in $F F$ is small (lower than relative 5\%) compared to the variation in photocurrent (relative 50\%), indicating similar charge carrier transport properties independent of the $\mathrm{Alq}_{3}$ thickness.

The efficiency shown in Fig. 5 reflects mainly the influence of capping layer thickness on photocurrent: since the variations of $V_{\mathrm{OC}}$ and $F F$ are small, $J_{\mathrm{SC}}$ determines $\eta$, representing a domination of the optical properties over electri-
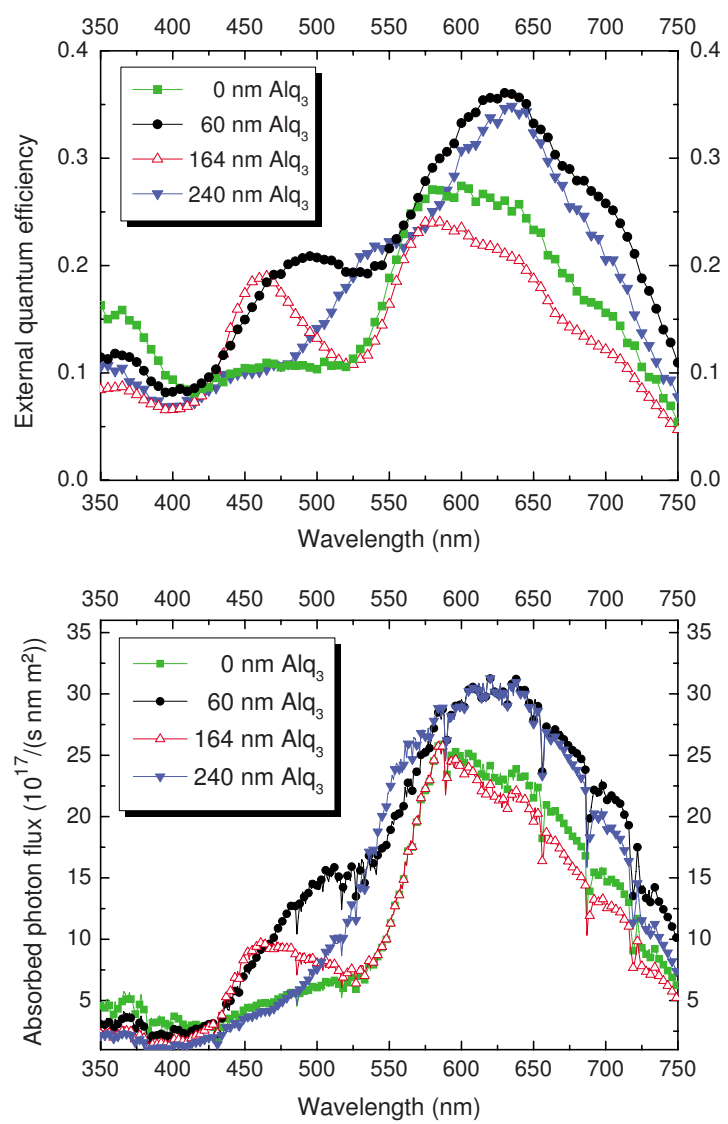

FIG. 6. (Color online) Top: EQE measurements of OSC with different $\mathrm{Alq}_{3}$ layer thicknesses, under illumination. Bottom: calculated absorbed photon flux of OSC with different $\mathrm{Alq}_{3}$ layer thicknesses, assuming $\mathrm{AM} 1.5 \mathrm{~g}$ illumination. Filled squares: $0 \mathrm{~nm} \mathrm{Alq}$. Filled circles: $60 \mathrm{~nm}$. Empty triangles: $164 \mathrm{~nm}$. Filled upside-down triangles: $240 \mathrm{~nm}$ capping layer.

cal influences. The oscillation of the saturation $S$ in the range from $\approx 1.18$ to 1.24 follows the same periodicity of the other characteristics, with $J(-1 \mathrm{~V}) / J_{\mathrm{SC}}$ being smallest for the highest currents and efficiencies and vice versa. Generally, the saturation is attributed to parallel resistance and leakage currents, e.g., due to morphological defects. In our case, the only variation is in the capping layer, so that we do not expect a change in parallel resistance. Hence, changes in the saturation must originate from the optical field, which in turn enhances or lowers the contributions from certain layers or materials. While the exact mechanisms are not clear, EQE measurements (Fig. 6) and optical simulations (Fig. 7) may indicate that excitons generated in $\mathrm{ZnPc}$ and intrinsic $\mathrm{C}_{60}$ are dissociated, and afterwards extracted, with higher efficiency compared to excitons from $\mathrm{C}_{60}$ in the BHJ. At $164 \mathrm{~nm} \mathrm{Alq}{ }_{3}$ thickness (high saturation), the contribution of $\mathrm{C}_{60}$ in the $\mathrm{BHJ}$ to overall performance is relatively strong; at $0 \mathrm{~nm}$ and $240 \mathrm{~nm}$, the photocurrent originates mostly from $\mathrm{ZnPc}$ with only low EQE below $500 \mathrm{~nm}$, leading to similar saturation. The best device with $60 \mathrm{~nm} \mathrm{Alq}$ is dominated by $\mathrm{ZnPc}$, with higher field amplitudes in the $\mathrm{C}_{60}$ absorption range reaching into the pure, intrinsic $\mathrm{C}_{60}$ layer. Overall, this may hint at slightly less efficient exciton dissociation from $\mathrm{C}_{60}$ in the BHJ.

The dependency of all main OSC characteristics of $\mathrm{Alq}_{3}$ thickness is explained as follows: the capping layer acts as 

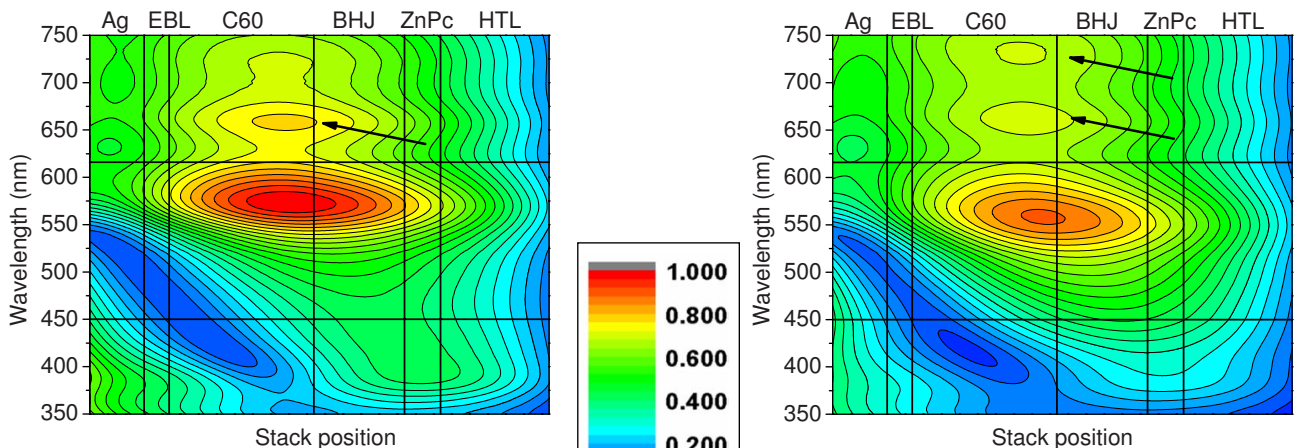

Top: $0 \mathrm{~nm} \mathrm{Alq}$; bottom: $164 \mathrm{~nm} \mathrm{Alq}{ }_{3}$
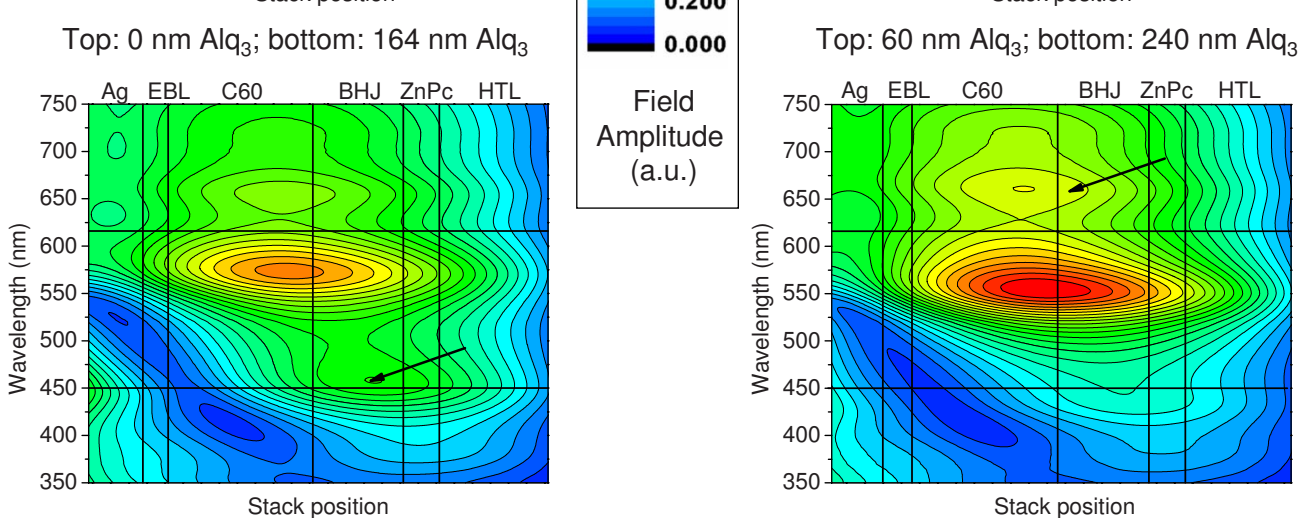

Field

Amplitude

(a.u.)

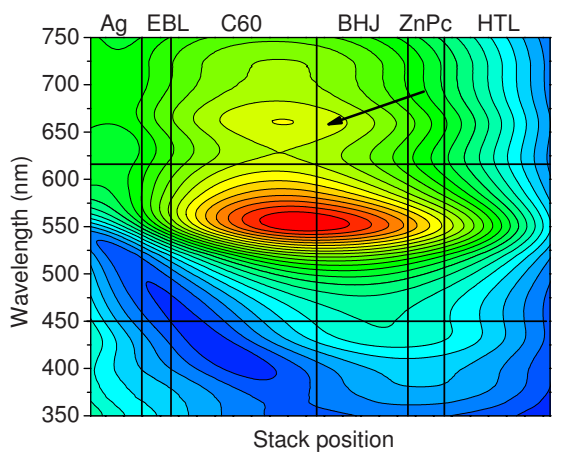

FIG. 7. (Color online) Normalized field amplitudes in the OSC stack with $0 \mathrm{~nm}$ (top left), $60 \mathrm{~nm}$ (top right), $164 \mathrm{~nm}$ (bottom left), and $240 \mathrm{~nm}$ (bottom right) $\mathrm{Alq}_{3}$ layer thickness. The $\mathrm{Alq}_{3}$ layers and the $\mathrm{Al}$ back contacts are not shown to achieve better visibility of the field in the active layers $\left(\mathrm{C}_{60}\right.$, $\mathrm{BHJ}$, and intrinsic $\mathrm{ZnPc})$. The horizontal lines show major absorption peaks of $\mathrm{C}_{60}(450 \mathrm{~nm})$ and $\mathrm{ZnPc}(630 \mathrm{~nm})$.

dielectric antireflection layer that modifies the interface between metal top contact $(\mathrm{Al} / \mathrm{Ag})$ and ambient air. This leads to an increased light transmission through the metal contact into the solar cell, ${ }^{17}$ depending on the capping layer thickness and material. Consequently, the $\mathrm{Alq}_{3}$ acts as external spacer layer which influences the incoming light wave within the organic stack. The distribution of the optical field within the active part of the stack $\left(\mathrm{ZnPc}\right.$ and $\left.\mathrm{C}_{60}\right)$ can be influenced by the capping layer thickness in such a way that a high field intensity can be shifted, e.g., into the transparent hole transport layer (leading to low absorption and resulting in low photocurrent) or directly into the absorber, explaining high photocurrents. The optical effects are now discussed in more detail.

Figure 6 (top) shows measurements of EQE resolved by wavelength. As expected, the data show significantly higher $\mathrm{EQE}$ in most of the visible spectrum for $60 \mathrm{~nm}$ capping compared to the sample without any $\mathrm{Alq}_{3}$, corresponding to the increased photocurrent. However, when considering only the antireflection effect of the capping layer, one should expect an increase in $\mathrm{EQE}$ in the absorption wavelengths of $\mathrm{C}_{60}$ (mainly 400-500 nm, peak at $450 \mathrm{~nm}$, as measured from thin film) and $\mathrm{ZnPc}$ (mainly 600-750 nm, peaks at 630 and 704 $\mathrm{nm}$, as measured from thin film). Instead, EQE data reveal a complex development of different peak features, strongly dependent on $\mathrm{Alq}_{3}$ thickness. For $0 \mathrm{~nm} \mathrm{Alq}$, one observes an overlap of $\mathrm{C}_{60}$ and $\mathrm{ZnPc}$ absorption. Upon addition of $60 \mathrm{~nm}$ $\mathrm{Alq}_{3}$, the $\mathrm{ZnPc}$ contribution to $\mathrm{EQE}$ from $600-750 \mathrm{~nm}$ is increased, alongside with an improvement from 450 to 530 $\mathrm{nm}$ in the $\mathrm{C}_{60}$ absorption range.

When using a thicker $\mathrm{Alq}_{3}$ layer, the antireflection effect remains; however, at $164 \mathrm{~nm} \mathrm{Alq}{ }_{3}$ the EQE decreases drastically in the $\mathrm{ZnPc}$ range $(630-700 \mathrm{~nm})$, dropping below $20 \%$ to even lower values compared to the sample without capping layer. It is striking that in contrast with this, EQE is increased at the $\mathrm{C}_{60}$ absorption maximum at $450 \mathrm{~nm}$, despite an overall smaller photocurrent. This indicates that for 164 $\mathrm{nm}$ capping layer thickness, the device stack is optimized specifically for absorption at this wavelength. $\mathrm{C}_{60}$ exhibits absorption at $350 \mathrm{~nm}$, for which the encapsulation glass is still transparent. As Fig. 6 shows, the EQE at $350 \mathrm{~nm}$ is lowest for $164 \mathrm{~nm}$ capping layer, demonstrating that the capping cannot only be used to strengthen the effect of absorber layers, but also to emphasize specific wavelength ranges.

Higher capping layer thicknesses lead to the second efficiency maximum, as shown for $240 \mathrm{~nm} \mathrm{Alq}$. Here, the $\mathrm{ZnPc}$ absorption is enhanced and leads to higher photocurrents, reflected in increased EQE from 550-750 nm compared to $164 \mathrm{~nm} \mathrm{Alq}_{3}$ thickness. Overall, the sharp increase especially at $630 \mathrm{~nm}$ leads to an increased $J_{\mathrm{SC}}$. Compared to all other capping layer thicknesses, at $240 \mathrm{~nm}$ thickness the contribution of $\mathrm{C}_{60}$ becomes extremely small, indicating a low field intensity at $450 \mathrm{~nm}$ wavelength in the fullerene.

Figure 6 (bottom) shows the spectral absorbed photon flux in the OSC active layers as obtained from simulations, assuming AM 1.5g illumination. Differences of EQE and simulation are to be expected because the optical model does not account for electrical effects (that is exciton and charge carrier dynamics, and electrical losses). Generally, the simulation results are in good qualitative agreement with the experimental data in Fig. 6 (top): the increased contribution of $\mathrm{C}_{60}$ for $164 \mathrm{~nm}$ capping is reflected, and the increase in ab- 


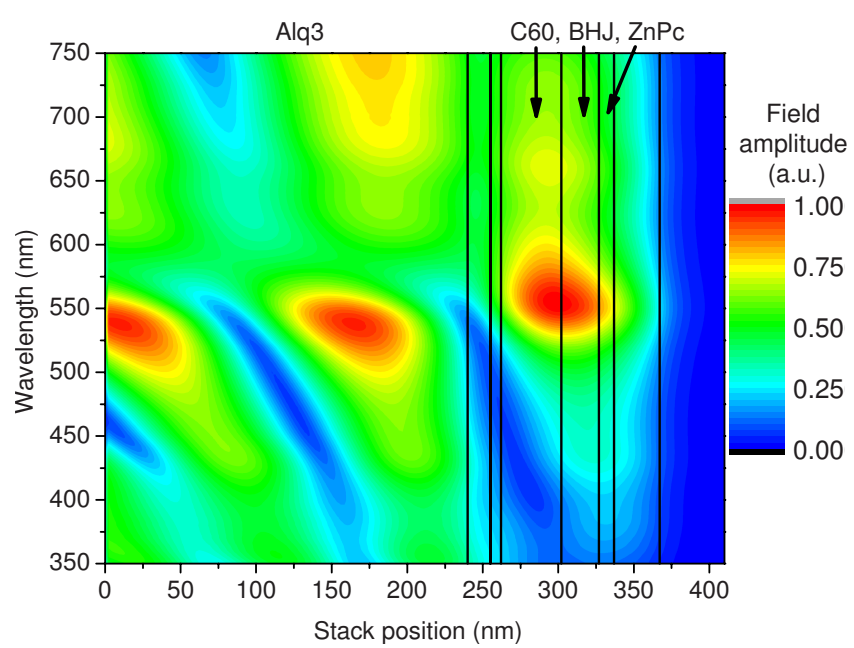

FIG. 8. (Color online) Normalized field amplitude in an OSC with $240 \mathrm{~nm}$ $\mathrm{Alq}_{3}$ capping layer in the complete device stack. The absorbing materials $\left(\mathrm{C}_{60}, \mathrm{BHJ}\right.$, and intrinsic $\left.\mathrm{ZnPc}\right)$ are marked to show their positions.

sorbed photon flux at $500 \mathrm{~nm}$ for $60 \mathrm{~nm} \mathrm{Alq}$ is evident, which is the main difference between the first $\left(60 \mathrm{~nm} \mathrm{Alq}_{3}\right)$ and second $(240 \mathrm{~nm} \mathrm{Alq} 3)$ efficiency maxima.

The normalized optical field distributions of OSC with 0 , 60,164 , and $240 \mathrm{~nm}$ capping layer thickness are illustrated in Fig. 7. In all cases, the capping layers and bottom electrodes $(100 \mathrm{~nm} \mathrm{Al})$ are omitted in the contour plots. Arrows show key features, e.g., field maxima in absorbing layers. Many features of the EQE measurements are reflected in these plots: the overall field distribution for $0 \mathrm{~nm} \mathrm{Alq}$ is reasonable for $\mathrm{ZnPc}$ absorption $(600-700 \mathrm{~nm})$ in BHJ and intrinsic $\mathrm{ZnPc}$ layers. The high amplitude at $570 \mathrm{~nm}$ is also visible in the EQE. However, due to high external reflection, overall device performance is low. For $60 \mathrm{~nm} \mathrm{Alq} 3$, we observe a widely spread relatively high field in $\mathrm{BHJ}$ and $\mathrm{ZnPc}$. Parts of the second maximum at $730 \mathrm{~nm}$ reach into the active layers, leading to a corresponding shoulder in the EQE. Low contributions are expected from the low amplitude in the 350 $\mathrm{nm}$ range in the $\mathrm{C}_{60}$ and $\mathrm{BHJ}$ layers. At $164 \mathrm{~nm} \mathrm{Alq}$, the field amplitude at $600-700 \mathrm{~nm}$ in the active layers is weak; however, a small maximum at $450 \mathrm{~nm}$ in the $\mathrm{BHJ}$ leads to relatively high $\mathrm{EQE}$ due to absorption of $\mathrm{C}_{60}$ in this layer. Finally, $240 \mathrm{~nm} \mathrm{Alq}$ lead to only small photocurrents from $\mathrm{C}_{60}$, while a small maximum in the $\mathrm{ZnPc}$ range explains the high EQE in Fig. 6 (top).

The normalized optical field amplitude of a complete stack, including $240 \mathrm{~nm} \mathrm{Alq}{ }_{3}$ and a thick bottom Al back contact, is shown in Fig. 8. An oscillating behavior of field minima and maxima in the wavelength ranges of $\approx 450-600 \mathrm{~nm}$ is observed throughout the stack, with a periodicity of $\approx 150 \mathrm{~nm}$. In this parameter range, no periodicity is detected from 600 to $750 \mathrm{~nm}$, which underlines the importance of device design for materials with narrow $a b-$ sorption bands.

The differential photon rate profiles in Fig. 9 show the total number of absorbed photons per unit time, unit surface, and unit propagation length, depending on the position in the stack. It is shown that the absorption of hole transporter, exciton blocker, and capping layer is negligible, whereas the

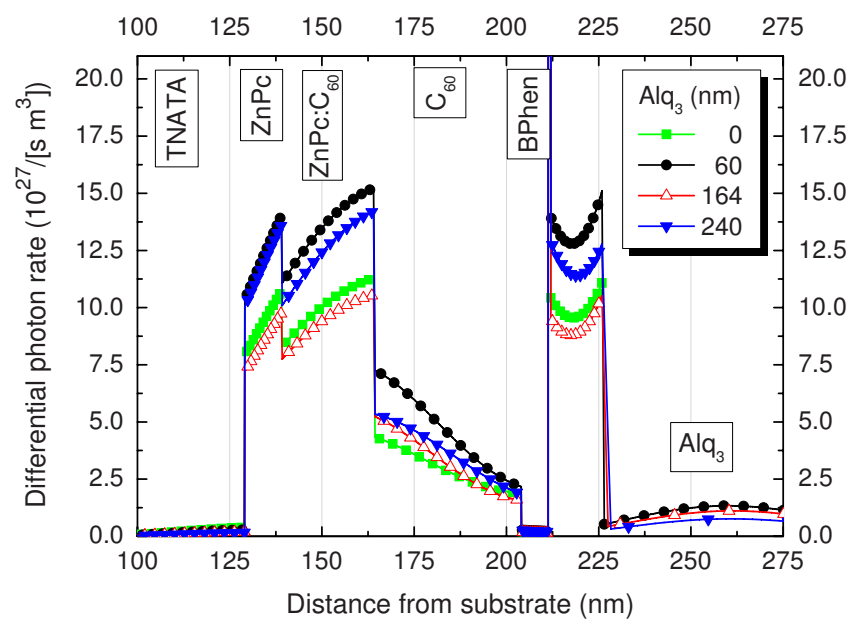

FIG. 9. (Color online) Absorbed total number of photons per unit time and unit area per nanometer, depending on the stack position. Plotted as distance from substrate (glass), omitting the $100 \mathrm{~nm}$ Al bottom electrode. Filled squares: $0 \mathrm{~nm} \mathrm{Alq}$. Filled circles: $60 \mathrm{~nm}$. Empty triangles: $164 \mathrm{~nm}$. Filled upside-down triangles: $240 \mathrm{~nm}$ capping layer.

transparent metal contact leads to parasitic absorption. Comparing the different capping layer thicknesses and taking no capping as reference, the addition of $60 \mathrm{~nm} \mathrm{Alq}{ }_{3}$ improves absorption in every layer, as inferred from EQE. $164 \mathrm{~nm}$ $\mathrm{Alq}_{3}$ actually lead to improved absorption in the $\mathrm{C}_{60}$, but due to the decrease in the $\mathrm{ZnPc}$-containing layers the overall current density is lowered. $240 \mathrm{~nm}$ improve photon harvesting in the intrinsic $\mathrm{ZnPc}$ layer, comparable to the effect of $60 \mathrm{~nm}$ $\mathrm{Alq}_{3}$, but due to a lower effect in the pure $\mathrm{C}_{60}$, this device is inferior in total power conversion efficiency compared to the optimal thickness of $60 \mathrm{~nm}$. Overall, from the comparison of experiments and simulations it is obvious that the $\mathrm{Alq}_{3}$ capping layer can strongly influence the optical properties of OSCs, and by careful determination of the thickness of the organic capping layer, wavelength- and layer-selective absorption enhancement is possible.

\section{CONCLUSION}

In summary, ITO-free inverted organic bulk heterojunction solar cells based on a $\mathrm{ZnPc}: \mathrm{C}_{60}$ heterojunction with different capping layer thicknesses are presented. The effect of an $\mathrm{Alq}_{3}$ capping layer on photocurrent, efficiency, saturation, open circuit voltage, and fill factor is characterized. Selective absorption of different materials in the stack at selective wavelength ranges is discussed, using EQE and current voltage measurements. Combined with numerical calculations, it is shown that the observed variations are mainly due to optical effects within the solar cell stack itself. A capping layer of $\mathrm{Alq}_{3}$ does not only have the potential to improve solar cell efficiency by $\approx 50 \%$, but can also be used to tailor field distribution in the stack or increase the efficiency of specific absorber layers, which is a major issue in the design of stacked tandem cells.

\section{ACKNOWLEDGMENTS}

This work is funded by the Bundesministerium für Bildung und Forschung in the framework of the InnoProfile 
project (Grant No. 03IP602). The authors thank the referee for the thorough review and stimulating comments.

${ }^{1}$ C. W. Tang, Appl. Phys. Lett. 48, 183 (1986).

${ }^{2} 2 \mathrm{~cm}^{2}$ small-molecule OSC, made by heliatek/IAPP, measured by ISE (Freiburg, Germany) in 2009 as having 6.07\% under standard reporting conditions.

${ }^{3}$ R. Timmreck, J. Meiss, A. Merten, R. Schueppel, M. Furno, C. Uhrich, W.-M. Gnehr, M. Pfeiffer, M. Riede, and K. Leo, "Realization and Characterization of Small Molecule Tandem Organic Solar Cells," Proceedings of the 24th EU PVSEC, pp. 89-92 (2009).

${ }^{4} 0.047 \mathrm{~cm}^{2}$ polymer OSC, made by Solarmer, measured by NREL in 2009 as having $7.9 \%$ under standard reporting conditions.

${ }^{5}$ J. Meiss, C. L. Uhrich, K. Fehse, S. Pfuetzner, M. K. Riede, and K. Leo, Proc. SPIE 7002, 700210 (2008).

${ }^{6}$ B. Zimmermann, M. Glatthaar, M. Niggemann, M. K. Riede, A. Hinsch, and A. Gombert, Sol. Energy Mater. Sol. Cells 91, 374 (2007).

${ }^{7}$ J. Meiss, M. K. Riede, and K. Leo, J. Appl. Phys. 105, 063108 (2009).

${ }^{8}$ T. Oyamada, Y. Sugawara, Y. Terao, H. Sasabe, and C. Adachi, Jpn. J. Appl. Phys., Part 1 46, 1734 (2007).

${ }^{9}$ K. Schulze, C. Uhrich, R. Schueppel, K. Leo, M. Pfeiffer, E. Brier, E. Reinhold, and P. Baeuerle, Adv. Mater. (Weinheim, Ger.) 18, 2872 (2006).

${ }^{10}$ J. Wu, Z. Bao, Z. Liu, Y. Chen, and P. Peumans, Appl. Phys. Lett. 92 $263302(2008)$

${ }^{11}$ J.-Y. Lee, S. T. Connor, Y. Cui, and P. Peumans, Nano Lett. 8, 689 (2008).

${ }^{12}$ M. W. Rowell, M. A. Topinka, M. D. McGehee, H.-J. Prall, G. Dennler, N. S. Sariciftci, L. Hu, and G. Gruner, Appl. Phys. Lett. 88, 233506 (2006).

${ }^{13}$ J. van de Lagemaat, T. M. Barnes, G. Rumbles, S. E. Shaneen, T. J. Coutts, C. Weeks, I. Levitsky, J. Peltola, and P. Glatkowsky, Appl. Phys. Lett. 88, 233503 (2006).

${ }^{14}$ Z. Wu, Z. Chen, X. Du, J. M. Logan, J. Sippel, M. Nikolou, K. Kamaras, J. R. Reynolds, D. B. Tanner, A. F. Hebard, and A. G. Rinzler, Science
305, 1273 (2004).

${ }^{15}$ R. Schueppel, R. Timmreck, N. Allinger, T. Mueller, M. Furno, C. Uhrich, K. Leo, and M. Riede, J. Appl. Phys. 107, 044503 (2010).

${ }^{16}$ B. O'Connor, K. H. An, K. P. Pipe, Y. Zhao, and M. Shtein, Appl. Phys. Lett. 89, 233502 (2006).

${ }^{17}$ J. Meiss, N. Allinger, M. K. Riede, and K. Leo, Appl. Phys. Lett. 93, 103311 (2008)

${ }^{18}$ Used for better processibility, comparable in performance to the commonly available 2,3,5,6-tetrafluoro-7,7,8,8-tetracyanoquinodimethane (F4TCNQ); for a comparison of NDP2 and F4-TCNQ, see S. Reineke, F. Lindner, G. Schwartz, N. Seidler, K. Walzer, B. Lüssem, and K. Leo, Nature 459, 234 (2009); and G. Schwartz, T. H. Ke, C. C. Wu, K. Walzer, and K. Leo, Appl. Phys. Lett. 93, 073304 (2008).

${ }^{19}$ T. Fritz, J. Hahn, and H. Boettcher, Thin Solid Films 170, 249 (1989).

${ }^{20}$ P. Würfel, Chimia 61, 770 (2007).

${ }^{21}$ M. C. Scharber, D. Muehlbacher, M. Koppe, P. Denk, C. Waldauf, A. J. Heeger, and C. J. Brabec, Adv. Mater. (Weinheim, Ger.) 18, 789 (2006).

${ }^{22}$ K. L. Mutolo, E. I. Mayo, B. P. Rand, S. R. Forrest, and M. E. Thompson, J. Am. Chem. Soc. 128, 8108 (2006).

${ }^{23}$ C. J. Brabec, A. Cravino, D. Meissner, N. S. Sariciftci, T. Fromherz, M. T. Rispens, L. Sanchez, and J. C. Hummelen, Adv. Funct. Mater. 11, 374 (2001).

${ }^{24}$ A. Gadisa, M. Svensson, M. R. Andersson, and O. Inganas, Appl. Phys. Lett. 84, 1609 (2004).

${ }^{25}$ M. Riede, T. Mueller, W. Tress, R. Schueppel, and K. Leo, Nanotechnology 19, 424001 (2008).

${ }^{26} \mathrm{P}$. Würfel, Physics of Solar Cells (Wiley VCH, New York, 2005).

${ }^{27}$ N. Li, B. E. Lassiter, R. R. Lunt, G. Wei, and S. R. Forrest, Appl. Phys. Lett. 94, 023307 (2009).

${ }^{28}$ B. P. Rand, D. P. Burk, and S. R. Forrest, Phys. Rev. B 75, 115327 (2007).

${ }^{29}$ S. Pfuetzner, A. Petrich, C. Malbrich, J. Meiss, M. Koch, M. K. Riede, M. Pfeiffer, and K. Leo, Proc. SPIE 6999, 69991M (2008). 